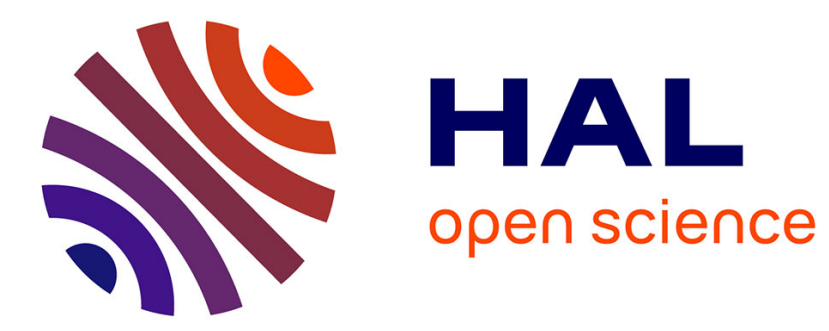

\title{
Effect of in-plane ordering on dielectric properties of highly 111-oriented bismuth-zinc-niobate thin films
}

A. Le Febvrier, Stephanie Deputier, Valérie Demange, V. Bouquet, A. Galca, A. Iuga, L. Pintilie, Maryline Guilloux-Viry

\section{- To cite this version:}

A. Le Febvrier, Stephanie Deputier, Valérie Demange, V. Bouquet, A. Galca, et al.. Effect of in-plane ordering on dielectric properties of highly 111-oriented bismuth-zinc-niobate thin films. Journal of Materials Science, 2017, 52 (19), pp.11306-11313. 10.1007/s10853-017-1297-x . hal-01562047

\section{HAL Id: hal-01562047 \\ https://hal-univ-rennes1.archives-ouvertes.fr/hal-01562047}

Submitted on 13 Jul 2017

HAL is a multi-disciplinary open access archive for the deposit and dissemination of scientific research documents, whether they are published or not. The documents may come from teaching and research institutions in France or abroad, or from public or private research centers.
L'archive ouverte pluridisciplinaire HAL, est destinée au dépôt et à la diffusion de documents scientifiques de niveau recherche, publiés ou non, émanant des établissements d'enseignement et de recherche français ou étrangers, des laboratoires publics ou privés. 


\section{Effect of in-plane ordering on dielectric properties of highly}

\section{$\{111\}$ oriented bismuth zinc niobate thin films}

A. Le Febvrier, ${ }^{\mathrm{a}, 1}$ S. Députier, ${ }^{* a}$ V. Demange, ${ }^{\mathrm{a}}$ V. Bouquet, ${ }^{\mathrm{a}}$ A.C. Galca, ${ }^{\mathrm{b}}$ A. Iuga, ${ }^{\mathrm{b}}$ L.

$$
\text { Pintilie, }{ }^{\mathrm{b}} \text { M. Guilloux-Viry }{ }^{\mathrm{a}}
$$

${ }^{a}$ Institut des Sciences Chimiques de Rennes, UMR CNRS 6226, Université de Rennes 1, Campus de Beaulieu, 35042 Rennes Cedex, France

${ }^{\mathrm{b}}$ National Institute of Materials Physics, Atomistilor 405A, 077125 Magurele, Ilfov, Romania

${ }^{1}$ Present address: Thin Film Physics Group, Department of Physics, Chemistry, and Biology (IFM), Linköping University, SE-58183 Linköping, Sweden.

corresponding authors:

Stéphanie Députier: email adress: stephanie.deputier@univ-rennes1.fr

ORCID identifier: 0000-0002-2813-2633

phone number: $33(0) 223236761$

Aurelian Catalin Galca: email adress: ac galca@,infim.ro

ORCID identifier: 0000-0002-1914-4210

phone number: +40212418132

Email addresses and ORCID identifiers of other authors:

Arnaud Le Fevrier: arnaud.le.febvrier@liu.se ; 0000-0002-3059-7392

Valérie Bouquet: valerie.bouquet@,univ-rennes1.fr ; 0000-0003-2472-6853

Valérie Demange: valerie.demange@univ-rennes1.fr; 0000-0002-8153-2660

Alin Iuga: iuga@,infim.ro ; 0000-0002-8588-0910

Lucian Pintilie: pintilie@,infim.ro ; 0000-0002-4934-2912

Maryline Guilloux-Viry: maryline.guilloux-viry@univ-rennes1.fr ;

0000-0001-7773-1643 


\section{$\underline{\text { Abstract }}$}

$\mathrm{Bi}_{1.5-\mathrm{x}} \mathrm{Zn}_{0.92-\mathrm{y}} \mathrm{Nb}_{1.5} \mathrm{O}_{6.92-\delta}(\mathrm{BZN})$ thin films were grown by pulsed laser deposition on two different Pt-covered substrates, namely textured $\{111\} \mathrm{Pt} / \mathrm{TiO}_{2} / \mathrm{SiO}_{2} /(100) \mathrm{Si}$ substrate $(\mathrm{Pt} / \mathrm{Si})$ and epitaxial $\{111\} \mathrm{Pt} / \mathrm{R}$-plane sapphire substrate $(\mathrm{Pt} / \mathrm{sapphire})$. In both cases, the BZN films present $\{111\}$ and $\{100\}$ out-of-plane orientations, in relative ratios of $65 / 35$ on $\mathrm{Pt} / \mathrm{Si}$, and $80 / 20$ on $\mathrm{Pt} /$ sapphire, respectively. The film grown on $\mathrm{Pt} / \mathrm{Si}$ is textured, while the film deposited on Pt/sapphire presents epitaxial-like relationships with the substrate, for both out-of-plane orientations. Dielectric measurements were performed on both types of thin films, using Pt/BZN/Pt planar capacitor structures. The $\mathrm{BZN} / \mathrm{Pt} /$ sapphire film presents higher dielectric constant (245 at $100 \mathrm{kHz}$ ) and higher tunability $(12 \%$ at $600 \mathrm{kV} / \mathrm{cm})$ than the BZN/Pt/Si film (200;6\%), while the dielectric losses values are nearly the same $(\sim 0.05)$.

Keywords : BZN; Bismuth based pyrochlore; thin films; dielectric properties

\section{Introduction}

Nowadays, the field of telecommunications arouses a strong interest in wireless technologies (e.g. Bluetooth, internet or Personal Navigation Device) which are added 
on the same equipment (e.g. mobile phone). All these technologies add value and/or space in the equipment, being detrimental to users' requirements in terms of size and cost. Therefore, reconfigurable devices that allow for example to change characteristics by a voltage application, have great potential. Among the studied materials to be used in such hardware, ferroelectrics in thin films form are widely investigated due to a high dielectric permittivity that can be driven by an external DC electric field. This property allows the elaboration of tunable and miniaturized microwave devices for various applications, such as planar capacitors, phase shifters, tunable filters or_ENREF 2 coplanar waveguides [1-4]. However, despite their high tunability, main ferroelectric materials present high dielectric losses in the microwave frequency range which presently restrain their use in such components. More recently, interest has been focused on other dielectric, but non-ferroelectric, materials such as the bismuth-zinc-niobate pyrochlore $\mathrm{Bi}_{1.5-\mathrm{x}} \mathrm{Zn}_{0.92-\mathrm{y}} \mathrm{Nb}_{1.5} \mathrm{O}_{6.92-\delta}(\mathrm{BZN})$, which attracted a considerable attention for its integration in microwave devices $[5,6]$. Belonging to the dielectric relaxors family, the dielectric properties of this complex oxide depend on both temperature and frequency $[7,8]$. BZN thin films have been deposited by various processes, such as rf-magnetron sputtering [9, 10], pulsed laser deposition (PLD) [11-14] or solution chemistry based on the Pechini method [15]. Such thin films exhibited a moderate 
permittivity (150-200), low dielectric losses $\left(5.10^{-4}<\tan \delta<5.10^{-3}\right.$ at $\left.1 \mathrm{MHz}\right)[5,6,8$, $16,17]$ and a tunability up to $55 \%$ (under high electric field of $2.4 \mathrm{MV} / \mathrm{cm}$ ) [10].

Few papers reported the impact of the epitaxial growth of BZN thin films on their dielectric properties. Cao et al. compared the dielectric properties of polycrystalline films deposited on $\mathrm{Pt} / \mathrm{TiO}_{2} / \mathrm{SiO}_{2} / \mathrm{Si}$ and of (100) epitaxial thin film grown on $\mathrm{Nb}$-doped (100)- $\mathrm{SrTiO}_{3}((100) \mathrm{Nb}$ :STO) [11]; they reported that the polycrystalline thin films possess a higher permittivity (204) and a higher tunability $(8 \%$ at $750 \mathrm{kV} / \mathrm{cm})$ with higher dielectric losses $(0.008)$ than the (100) epitaxial films. Same authors also reported a study on the influence of the out-of-plane orientation of epitaxial thin films deposited on (100) and (110) Nb:STO; it was found that $\{111\}$-oriented thin films exhibit higher permittivity (155), higher tunability (6.5\% at $750 \mathrm{kV} / \mathrm{cm})$ and higher dielectric losses (0.02) than $\{100\}$-oriented films [18]_ENREF 14. Furthermore their investigation of the dependence of dielectric properties on the thickness in case of $\{100\}$-oriented films has shown that best results in terms of dielectric constant (122) and dielectric losses (0.004) are achieved for thick films $(700 \mathrm{~nm})$, while the thinnest films (150nm) exhibit lower dielectric constant (70) and much higher dielectric losses (0.01). 
The present study aims to investigate the impact on the dielectric properties of the in-plane ordering of BZN thin films grown on Pt, i.e. the in-plane structural orientation of the film in relation to that of the substrate and/or the bottom layer. The BZN thin films were deposited on two different electrodes: a textured $\{111\}$-oriented platinum electrode $(\mathrm{Pt} / \mathrm{Si})$ and a $\{111\}$ epitaxial grown platinum electrode (Pt/R-sapphire). Both electrodes are expected to promote a highly $\{111\}$ out-of-plane orientation of BZN, while an in-plane ordering of the crystallites might be achieved only on the epitaxial-like platinum electrode. The dielectric properties were investigated on metal/insulator/metal (MIM) Pt/BZN/Pt capacitor at $100 \mathrm{kHz}$ and under a maximum electric field of $600 \mathrm{kV} / \mathrm{cm}$. The influence of BZN epitaxial-like growth, related to the crystalline quality (i.e. textured or epitaxial growth) of the Pt bottom-electrode, on the dielectric properties of the thin films (permittivity and tunability) is discussed.

\section{Experimental procedure}

The BZN thin films were deposited on a commercial (Crystal GmbH) textured platinum layer grown on silicon with proper buffer layers $\{111\} \mathrm{Pt} / \mathrm{TiO}_{2} / \mathrm{SiO}_{2} /(100) \mathrm{Si}$ (thin film thereafter named "A") and on a homemade 200 nm-thick $\{111\}$ epitaxial platinum layer grown on R-plane sapphire (thin film thereafter named " $\mathrm{B}$ "). The 
homemade Pt layer was prepared by dc-sputtering at $450^{\circ} \mathrm{C}$, under an argon pressure of $10 \mathrm{~Pa}$, at a voltage of $-1.5 \mathrm{kV}$, the time of deposition being $20 \mathrm{~min}$ [19]. The BZN films were grown by pulsed laser deposition using a $\operatorname{KrF}$ excimer laser $(\lambda=248 \mathrm{~nm})$ and a stoichiometric $\mathrm{Bi}_{1.5} \mathrm{Zn}_{0.92} \mathrm{Nb}_{1.5} \mathrm{O}_{6.92-\delta}$ target sintered by a conventional ceramic method following the conditions described elsewhere $[12,20]$ ENREF 8. The BZN deposition parameters were as follows: fluence $-2 \mathrm{~J} / \mathrm{cm}^{2}$; frequency $-2 \mathrm{~Hz}$; temperature $-700^{\circ} \mathrm{C}$; target-substrate distance - $55 \mathrm{~mm}$; deposition time - $20 \mathrm{~min}$; and oxygen pressure - 30 Pa. These conditions were the proper ones to obtain highly $\{111\}$ oriented thin films on both substrates. For the X-ray diffraction (XRD) analysis, two diffractometers were used: a D8 Advance Brüker AXS $(\theta-2 \theta$ configuration) equipped with a monochromatized $\mathrm{Cu} \mathrm{K} \alpha_{1}$ radiation source and a four-circle texture instrument (D8 Discover Brüker AXS) equipped with a parallel beam $\mathrm{Cu} \mathrm{K} \alpha_{1}$ radiation in $\theta-2 \theta$, $\omega$, and $\varphi$ scan modes. The XRD peaks were fitted by using pseudo-Voigt functions (WinPLOTR software [21]) in order to determine peak positions and full-width-at-half-maxima (FWHM). The surface morphology and the thickness were determined via field-emission scanning electron microscopy (FE-SEM), using a JEOL JSM 6310F system working at a low accelerating voltage $(7 \mathrm{kV})$. The composition of the films was analyzed by energy-dispersive X-ray spectroscopy (EDS), using a JEOL 
JSM 6400 scanning electron microscope equipped with an ISIS Oxford analyzer $(10 \mathrm{kV}$ was used as an accelerating voltage and $10 \mathrm{nA}$ as a beam current). The dielectric properties were evaluated using $\mathrm{Pt} / \mathrm{BZN} / \mathrm{Pt}$ planar capacitor structures. The $\mathrm{Pt}$ top electrodes, with an area of $0.2 \mathrm{~mm}^{2}$, were deposited by radio frequency sputtering through a shadow mask onto the surface of the films. The dielectric constant and dielectric losses were measured with a LCR HITESTER 3532-50 instrument.

\section{Results and discussion}

3.1. Films composition and morphology

$\mathrm{BZN} /\{111\} \mathrm{Pt} / \mathrm{TiO}_{2} / \mathrm{SiO}_{2} /(100) \mathrm{Si}$ (film A) and BZN/\{111\} Pt/R-sapphire (film B), were deposited from a stoichiometric $\mathrm{Bi}_{1.5} \mathrm{Zn}_{0.92} \mathrm{Nb}_{1.5} \mathrm{O}_{6.92-\delta}$ target. EDS measurements performed on the two samples led to an average composition of the BZN films corresponding to $\mathrm{Bi}_{1.3} \mathrm{Zn}_{0.5} \mathrm{Nb}_{1.5} \mathrm{O}_{6.92-\delta}$. Losses of bismuth and zinc from the target during deposition by PLD process have already been observed [12, 22]; these losses are related to the high volatility of those two elements under the conditions of pressure and temperature used during the deposition. Whatever the characteristics of the Pt electrodes, the obtained BZN thin films, with a thickness of $160 \mathrm{~nm}$, present a dense, homogeneous and crack free surface, as shown in figure 1. 

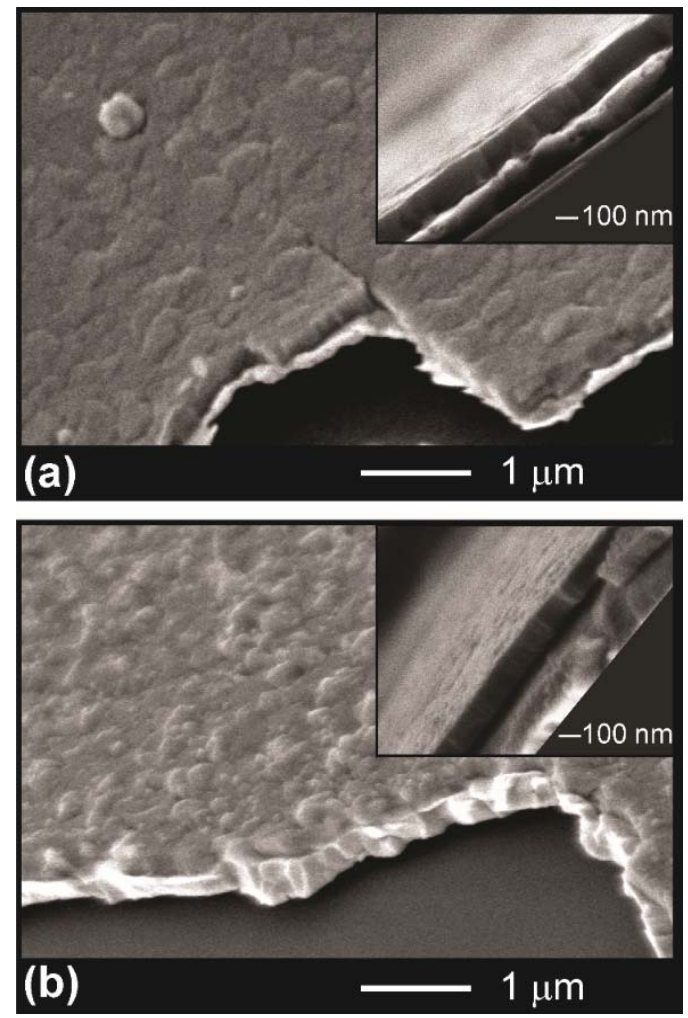

Fig 1 FE-SEM views at $45^{\circ}$ and cross-section views (insets) of BZN thin films grown on (a) a textured $\{111\} \mathrm{Pt} / \mathrm{TiO}_{2} / \mathrm{SiO}_{2} /(100) \mathrm{Si}$ substrate (film A) and (b) on an epitaxial $\{111\} \mathrm{Pt} / \mathrm{R}$-plane sapphire substrate (film B)

\subsection{Preferential orientations and epitaxial-like relationships}

The $\theta-2 \theta$ XRD patterns of the two BZN thin films, presented in figure 2, evidenced the single $\{111\}$ orientation of Pt (ICDD Powder Diffraction File (PDF) Card No. 04-0802; space group Fm3m (n²25); $a=3.9231 \AA$ ). In both cases, even with Bi and $\mathrm{Zn}$ deficiencies, the BZN cubic pyrochlore phase was obtained and no other phase was observed. The diffraction peaks were indexed considering the cubic pyrochlore structure with a unit-cell parameter equal to $a=10.566(4) \AA$ for the film A and $a=$ 
10.585(4) $\AA$ for the film B, these parameters being close to the bulk value [23] (ICDD Powder Diffraction File (PDF) Card No. 052-1770; space group Fd-3m (n²27); $a=$ $10.558 \AA)$.
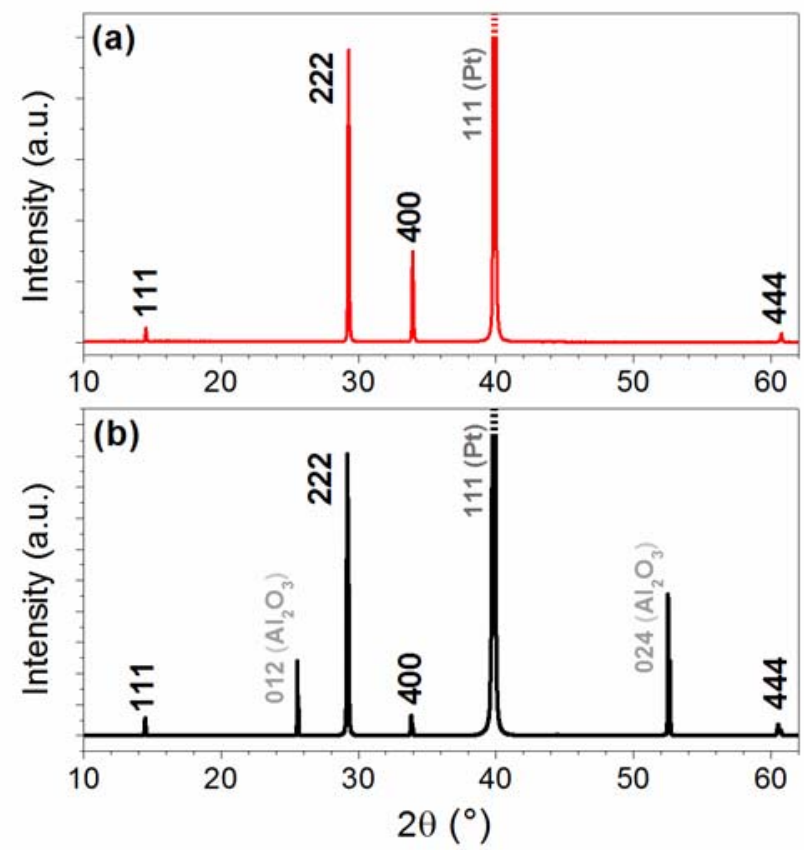

Fig 2 - $-2 \theta$ XRD patterns of the BZN thin films A (a) and B (b)

The two thin films are preferentially oriented along the $<111>$ directions with some secondary $<100>$ orientation. The fraction of $\{\mathrm{hkl}\}$ oriented grains of $\mathrm{BZN}\left(\mathrm{X}_{\mathrm{hkl}}\right)$ was estimated by the following formula (1) [12]:

$$
\frac{X_{\text {hkl }}}{X_{222}}=\frac{\left\{I_{\text {hkl }}\right\}_{\text {film }} /\left\{I_{\text {hkl }}\right\}_{\text {bulk }}}{\left\{I_{222}\right\}_{\text {film }} /\left\{I_{222}\right\} \text { bulk }} \text { and } \sum X_{\text {nkl }}=1 .
$$


$\left\{\mathrm{I}_{\mathrm{hkl}}\right\}_{\text {film }}$ is the normalized integral intensity of the $\{\mathrm{hkl}\}$ diffraction peak; this value is equal to the full-width-at-half-maximum (FWHM) of the $\{h k 1\}$ peak in the $\theta-2 \theta$ pattern multiplied by the integral intensity of the peak of the corresponding rocking-curve $\left(\omega\right.$-scan). $\left\{\mathrm{I}_{\mathrm{hkl}}\right\}_{\text {bulk }}$ is the intensity of the peak of bulk material after correction of the multiplicity. For the thin film A, $65 \%$ of the grains are oriented out-of-plane along the $<111>$ directions and $35 \%$ along the $<100>$ ones. For the thin film $\mathrm{B}$, the fraction of the crystallites oriented along the $<111>$ directions is higher and reaches $80 \%$ while a fraction of around $20 \%$ is calculated for the $<100>$ oriented crystallites.

The quality of the out-of-plane ordering (i.e. along the growth direction) was evaluated by performing $\omega$-scans around the 222 reflection of BZN. The value of the FWMH $(\Delta \omega)$ obtained from the $\omega$-scan pattern is $5.3^{\circ}$ for the film $\mathrm{A}$ and $0.3^{\circ}$ for the film B, that highlights a significant difference of out-of-plane ordering between the two thin films (Table I). This difference is mainly related to the crystalline quality of the platinum underneath layers. On R-plane sapphire, the epitaxial homemade $\{111\} \mathrm{Pt}$ exhibits a $\Delta \omega$ value of $0.3^{\circ}$ (figure 3-inset), while the commercial textured one has a $\Delta \omega$ value of $3.6^{\circ}$. 
Table I Relative fractions of $\{\mathrm{hkl}\}$-oriented crystallites and $\{100\}$ out-of-plane and in-plane ordering quality $(\Delta \omega$ and $\Delta \varphi)$ for thin films grown on a textured $\{111\} \mathrm{Pt} / \mathrm{SiO}_{2} / \mathrm{Ti} /(100) \mathrm{Si}$ substrate and on an epitaxial $\{111\} \mathrm{Pt} / \mathrm{R}-$ plane sapphire substrate.

\begin{tabular}{|c|c|c|c|c|c|}
\hline \multirow[t]{2}{*}{ Name } & \multirow[t]{2}{*}{ Substrate } & \multicolumn{2}{|c|}{$\begin{array}{c}\text { Fraction of } \\
\quad\{h k l\} \\
\text { orientation }\end{array}$} & \multirow{2}{*}{$\begin{array}{l}\text { Out-of-plane } \\
\text { ordering: } \\
\Delta \omega \text { of the } \\
222 \\
\text { reflection }\end{array}$} & \multirow{2}{*}{$\begin{array}{l}\text { In-plane } \\
\text { ordering: } \\
\Delta \varphi \text { of the } \\
\quad 400 \\
\text { reflection }\end{array}$} \\
\hline & & $\{111\}$ & $\{100\}$ & & \\
\hline $\begin{array}{c}\text { Thin film } \\
\text { A }\end{array}$ & $\begin{array}{c}\text { Textured } \\
\{111\} \mathrm{Pt} / \mathrm{SiO}_{2} / \mathrm{Ti} /(100) \mathrm{Si}\end{array}$ & $65 \%$ & $35 \%$ & $5.3^{\circ}$ & - \\
\hline $\begin{array}{c}\text { Thin film } \\
\text { B }\end{array}$ & $\begin{array}{c}\text { Epitaxial } \\
\{111\} \mathrm{Pt} / \mathrm{R}-\text { plane sapphire }\end{array}$ & $80 \%$ & $\sim 20 \%$ & $0.3^{\circ}$ & $0.9^{\circ}$ and $2.5^{\circ}$ \\
\hline
\end{tabular}

In order to characterize the in-plane ordering, $\varphi$-scans were performed on both

films. As expected, the thin film A did not show any in-plane ordering, due to the texture of the bottom Pt layer. The epitaxial growth of the preferential $\{111\}$ orientation of the Pt layer of thin film B was evidenced (bottom-panel of figure $3 ; 2 \theta=46.24^{\circ} ; \chi=$ $\left.54.74^{\circ}\right)$ ), in agreement with previous studies on Pt growth on R-plane sapphire $[24,25]$. Two sets of peaks shifted of $30^{\circ}$ were observed, corresponding to two in-plane orientations, with FWHM $\Delta \varphi$ of $0.8^{\circ}$ and $2.5^{\circ}$. These two in-plane orientations 
correspond to rotational twinning of Pt on sapphire that was fully described by Nefedov

et al. [24].

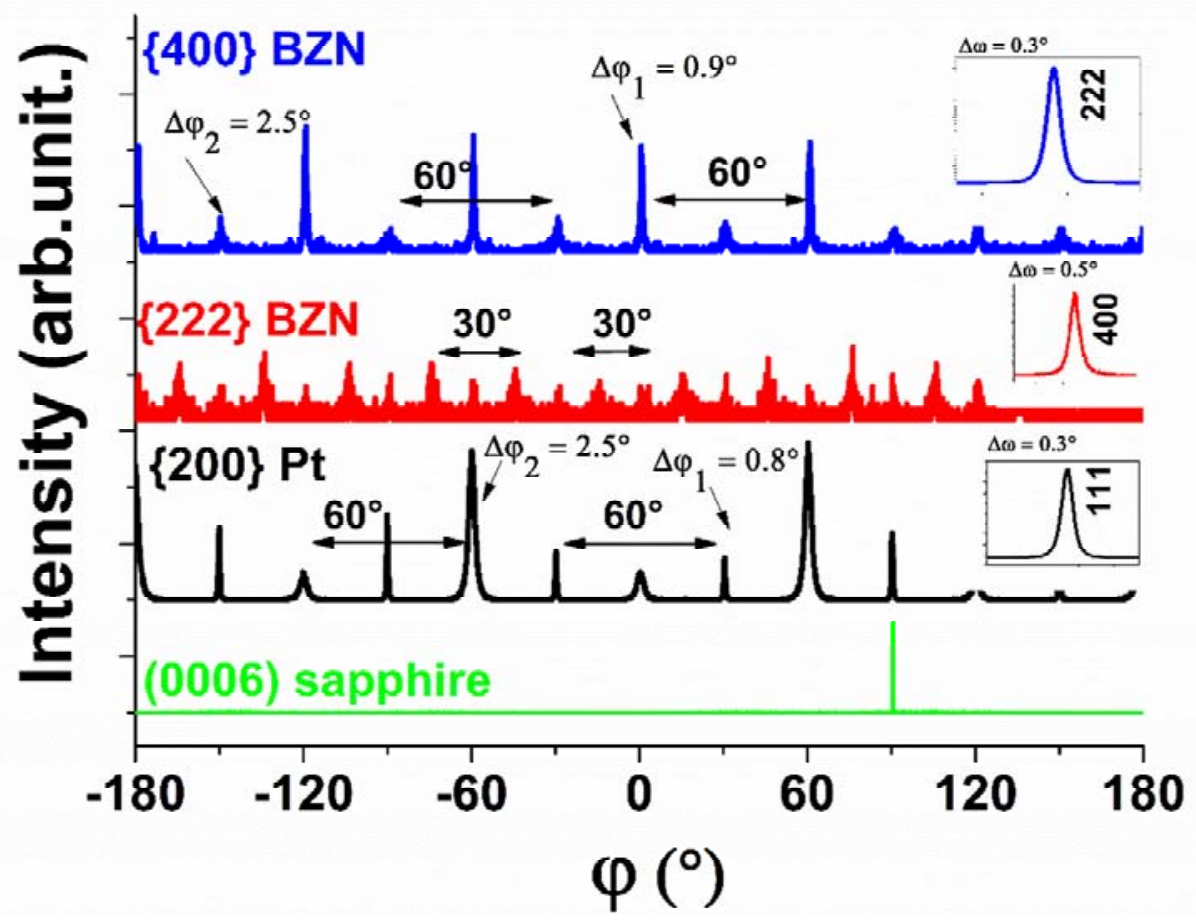

Fig 3 XRD $\varphi$-scan patterns of film B. From bottom to top: $\varphi$-scan of R-plane sapphire performed on (0006) plane; $\varphi$-scan of $\{111\}$-oriented Pt electrode performed on the 200 reflection; $\varphi$-scan of $\{100\}$-oriented BZN performed on the 222 reflection; $\varphi$-scan of $\{111\}$-oriented BZN performed on the 400 reflection. The corresponding $\omega$-scans are given in the inset for each XRD $\varphi$-scan pattern.

The in-plane ordering of the two $\{100\}$ and $\{111\}$ preferential orientations of the BZN layer (thin film B) was established by the $\varphi$-scans performed on 222 
(middle-panel in figure $3 ; 2 \theta=29.19^{\circ} ; \chi=54.74^{\circ}$ ) and 400 reflection (top-panel in figure $3 ; 2 \theta=33.88^{\circ} ; \chi=54.74^{\circ}$ ), respectively. Both $\varphi$-scans present peaks located at the same value than the one of the Pt bottom layer, and separated by $30^{\circ}$, with $\Delta \varphi$ equal to $0.9^{\circ}$ and $2.5^{\circ}$ for $\{222\}$, and $\sim 2.5^{\circ}$ for $\{400\}$. This correlation demonstrates that the in-plane ordering of BZN is induced by the in-plane ordering of the Pt. The $\varphi$-scan of the $\{100\}$ orientation presents in addition peaks located at $15^{\circ}$ of the previous ones, evidencing the presence of another in-plane ordering for this orientation. However, the intensity of all the peaks in this pattern is rather low which indicates that only some of the $\{100\}$-oriented crystallites are in-plane ordered. The different epitaxial-like relationships between BZN and Pt are illustrated on figure 4 and given in table II.

Table II Epitaxial-like relationships and mismatch values of the three BZN orientations on $\{111\} \mathrm{Pt}$ in the case of thin film B

\begin{tabular}{|c|c|c|}
\hline BZN orientation on $\{111\}$ Pt & Epitaxial-like relationships & Mismatch \\
\hline$\{100\} \mathrm{BZN}$ orientation 1 & $(100)_{\mathrm{BZN}} / /(111)_{\mathrm{Pt}}$ & $-8.64 \%$ \\
& {$[010]_{\mathrm{BZN}} / /[1-10]_{\mathrm{Pt}}$} & \\
\hline$\{100\} \mathrm{BZN}$ orientation 2 & $(100)_{\mathrm{BZN}} / /(111)_{\mathrm{Pt}}$ & \\
& {$[001]_{\mathrm{BZN}} / /[11-2]_{\mathrm{Pt}}$} & \\
& & \\
\hline
\end{tabular}




\begin{tabular}{|l|c|c|}
\hline & {$[001]_{\mathrm{BZN}} / /[21-3]_{\mathrm{Pt}}$} & \\
\hline$\{111\} \mathrm{BZN}$ orientation & $(111)_{\mathrm{BZN}} / /(111)_{\mathrm{Pt}}$ & $0.26 \%$ \\
& {$[1-10]_{\mathrm{BZN}} / /[1-10]_{\mathrm{Pt}}$} & \\
& {$[10-1]_{\mathrm{BZN}} / /[10-1]_{\mathrm{Pt}}$} & \\
\hline
\end{tabular}

In the case of $\{100\}$ preferential orientation, one BZN unit-cell can match two hexagonal Pt cells (Figure 4a, Table II) $\left([010]_{\mathrm{BZN}} / /[1-10]_{\mathrm{Pt}}\right)$, while a second face to face matching can be possible by overlapping a BZN unit-cell on two hexagonal Pt cells oriented along the [34-1] direction (Figure 4b, Table II). The mismatch in the first case is equal to $-8.64 \%$, and to $4.35 \%$ in the second case. In the $\varphi$-scan, the intensity of the peaks of this second ordering are consequently higher due to this lower mismatch. The high values of mismatch are also in agreement with the assumption that only a part of the $\{100\}$-oriented crystallites is in-plane ordered. The $\{111\}$ BZN growth on $\{111\} \mathrm{Pt}$ can be drawn as a hexagon-on-hexagon; in this case, three BZN hexagonal lattice units will correspond to four Pt hexagonal lattice units (Figure 4c) and the mismatch is very low $(0.26 \%)$ (Table II). 


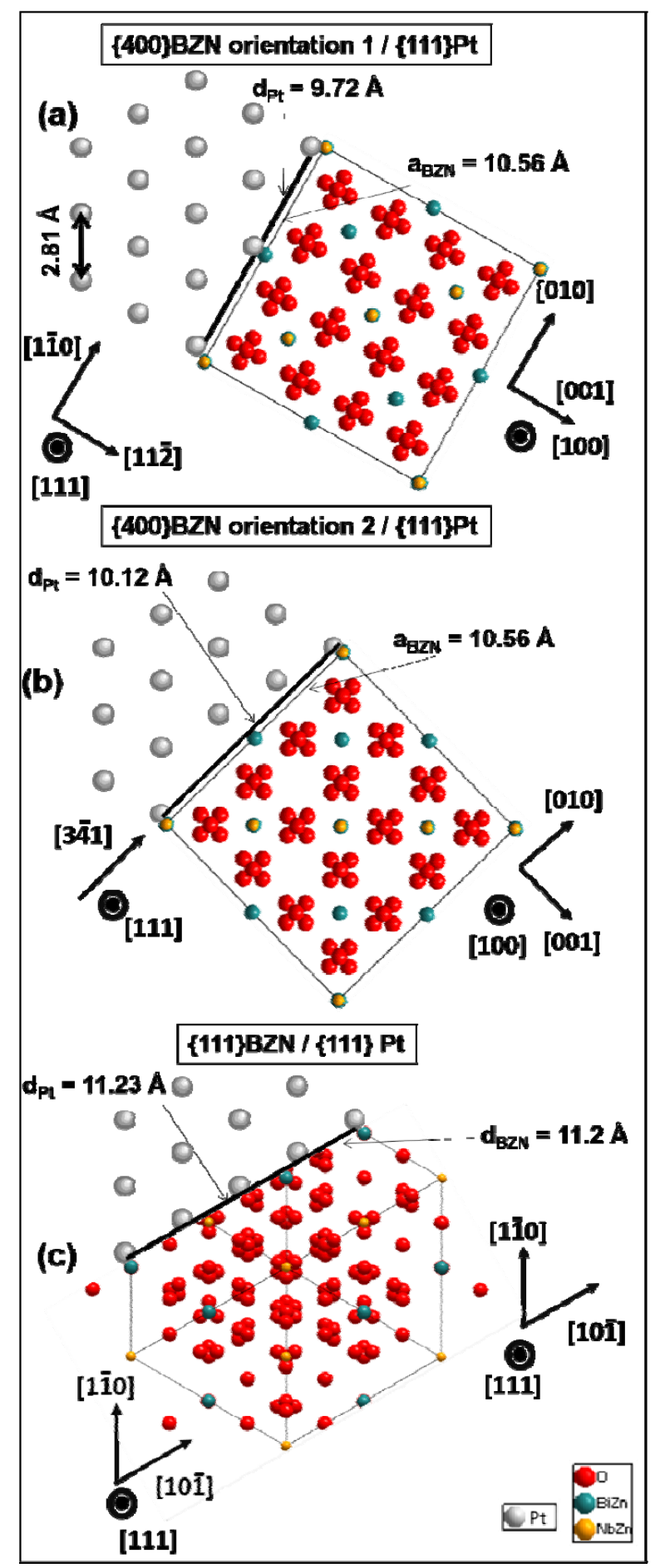


Fig. 4 Schemas of the coincidences between the $\{100\}$-oriented BZN cells on $\{111\} \mathrm{Pt}$ having two in-plane ordering (a and $b$ ), and between $\{111\}$-oriented BZN cells on $\{111\} \mathrm{Pt}$ (c) (for simplification purpose, only one (111) layer of $\mathrm{Pt}$ is displayed).

\subsection{Dielectric properties}

The dielectric measurements under a bias voltage (at $100 \mathrm{kHz}$ ) were performed on the two thin films in MIM configuration after the deposition of a Pt-top electrode (figure 5).

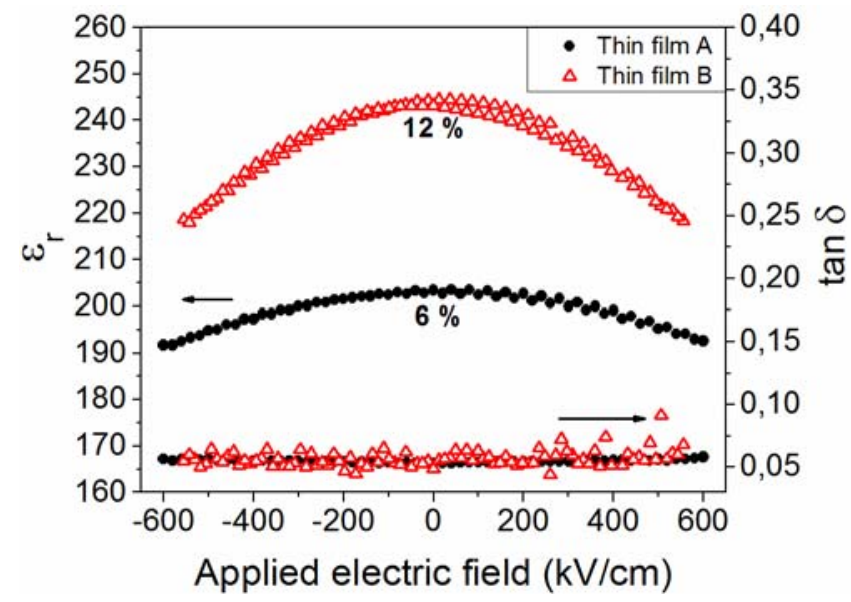

Fig. 5 DC bias field dependence of relative permittivity $\left(\varepsilon_{\mathrm{r}}\right)$ and dielectric losses $(\tan \delta)$ measured at $100 \mathrm{kHz}$ and $300 \mathrm{~K}$ of $\mathrm{Bi}_{1.3} \mathrm{Zn}_{0.5} \mathrm{Nb}_{1.5} \mathrm{O}_{6.92-\delta}$ films: $\mathrm{A}$ (circle) and $\mathrm{B}$ (triangle)

The thin film A presented a dielectric permittivity of 200 without applied electric field and a tunability of $6 \%$ under $600 \mathrm{kV} / \mathrm{cm}$. These values are close to those found in literature, for instance in reference [11] for a $c$-axis oriented BZN film. However, in the present study, the dielectric losses are high (0.05) compared to the best results reported in the literature; this could be linked to two main following factors: the thickness (160 
$\mathrm{nm})$ and the $\{111\}$ preferential orientation of the BZN film. Indeed, several studies on dielectric thin films $[18,26]$ have evidenced a thickness dependence of the dielectric losses: thinner films may induce higher dielectric losses correlated to the presence of higher leakage current and/or local strain with the in-plane ordering $[18,27]$. In the same way, in a comparative study of the dielectric properties of BZN films of different preferential orientations, $\{111\}$-oriented BZN films show higher loss tangent than $\{100\}$ ones [18]. Moreover, the thin film A has a columnar structure as observed on the FE-SEM cross-section view (figure 1) which may contribute to the relatively high dielectric losses, especially when measured in planar metal/insulator/metal capacitor geometry. For the thin film B, measurements under the same electric field exhibited a higher value of permittivity of 245 with a better tunability (12\%) while preserving the value of the dielectric losses $(\sim 0.05)$. The increase of dielectric permittivity and tunability could be related to the preferred $\{111\}$ orientation as shown by Cao et al. [18] who have obtained better dielectric properties for $\{111\}$ BZN thin films. In our study, by comparing films with the same thickness, we can state that the fraction of the $\{111\}$ orientation that increases from 65 to $80 \%$ between the film A and B influences the relative permittivity and the tunability. Epitaxial-like growth might have also its improving role, in agreement with a previous related study on $\mathrm{Ba}_{0.6} \mathrm{Sr}_{0.4} \mathrm{TiO}_{3}$ thin films 
where the authors concluded that the epitaxial growth is a key factor to increase the permittivity and the tunability [28].

The increase of the dielectric permittivity of preferentially oriented $\{111\} \mathrm{BZN}$ film may be correlated to the structure of the ideal $\mathrm{A}_{2} \mathrm{~B}_{2} \mathrm{O}_{6} \mathrm{O}^{\prime}$ pyrochlore which could be described using two networks, i.e. one consisting of octahedra $\mathrm{BO}_{6}\left((\mathrm{Nb}, \mathrm{Zn}) \mathrm{O}_{6}\right)$ and another one consisting of tetrahedra $\mathrm{O}^{\prime} \mathrm{A}_{2}\left(\mathrm{O}^{\prime}(\mathrm{Bi}, \mathrm{Zn})_{2}\right)$. These latter, connected by their corners, create an alignment of reversed tetrahedra along the $<111>$ directions (figure $6)$.

a)

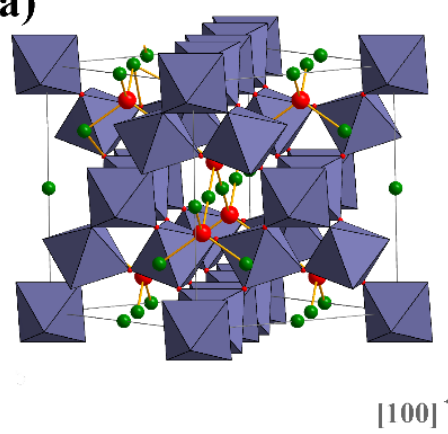

b)

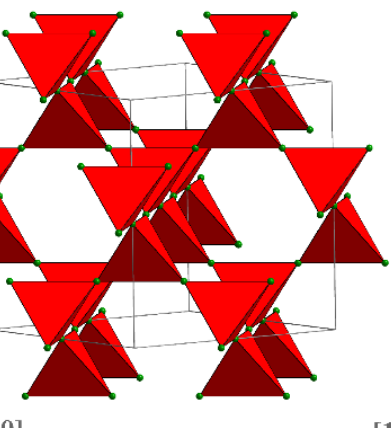

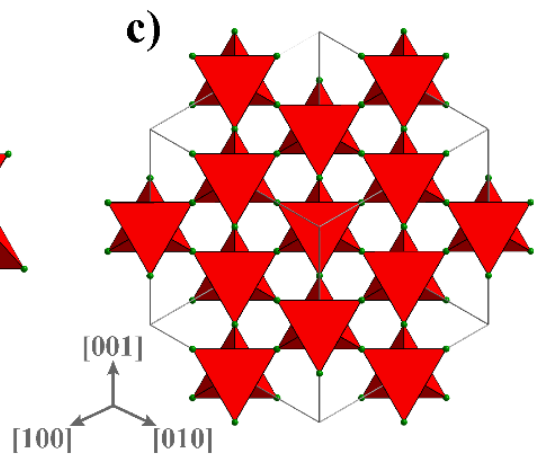

Fig. 6 Ideal cubic pyrochlore structure $\mathrm{A}_{2} \mathrm{~B}_{2} \mathrm{O}_{6} \mathrm{O}^{\prime}$ described with two networks: a) corner-connected octahedra $\mathrm{BO}_{6}$ and b) corner-connected tetrahedra $\mathrm{O}^{\prime} \mathrm{A}_{2} ;$ c) representation of the tetrahedron sub-network along the [111] direction. Blue and red polyhedra: $(\mathrm{Nb}, \mathrm{Zn}) \mathrm{O}_{6}$ and $\mathrm{O}^{\prime}(\mathrm{Bi}, \mathrm{Zn})_{2}$, respectively; Red and green spheres: oxygen and bismuth/zinc, respectively 
Further analyses on the possible arrangements of the $\mathrm{Bi}^{3+}$ and $\mathrm{Zn}^{2+}$ cations and vacancies in the A site and their effects on the local distortion of the pyrochlore have been carried out; however no definite conclusions have been reported [29, 30]. Several papers have discussed the possible mechanisms of the dielectric non-linearity in the bismuth pyrochlore materials [31-33]. It has been assumed that the electric field tunability is related with local hopping of ions in the A and O' positions of the pyrochlore structure although the origins are not yet clearly understood [31,32]. Wei et al. succeeded to calculate the tunability characteristic of $\mathrm{Bi}_{1.5} \mathrm{MgNb}_{1-\mathrm{x}} \mathrm{Ti}_{\mathrm{x}} \mathrm{O}_{7}$ pyrochlore thin films using a modified Tagantsev's model of hopping dipoles under random fields [31]. Two polarization mechanisms contribute to the permittivity of the Bi-based pyrochlore: the normal electronic and ionic polarization (non-tunable) and the hopping dipoles (tunable). The local hopping of ions in the $\mathrm{O}^{\prime} \mathrm{A}_{2}$ sub-network occurs among several local potential minima which seem to be situated along the $<111>$ direction of the pyrochlore.

\section{Conclusions}

Highly oriented BZN thin films with both $\{111\}$ and $\{100\}$ out-of-plane orientations have been deposited by PLD on two different Pt covered substrates. As 
expected, a textured $\{111\} \mathrm{Pt} / \mathrm{Si}$ substrate leads to a textured BZN thin film whereas an epitaxial growth of Pt on R-sapphire induces an in-plane ordering of BZN. For the latter, the epitaxial-like growth of $\{111\}$ BZN that is accompanied by the decrease of the $\{100\}$ secondary orientation, promotes better dielectric properties: a doubled tunability $(12 \%)$ and an increased dielectric permittivity (22\%), compared to those of the textured thin film. However, the dielectric losses, characteristic for such thin films, do not significantly get changed and remain high, partly due to the $\{111\}$ preferential orientation and the low thickness of the BZN film.

\section{Acknowledgments}

The authors acknowledge the Romanian Ministry of Research and

Innovation (core program / project PN-III-16-48-02) for their financial support. I.

Peron and F. Gouttefangeas are acknowledged for EDS analyses and J. Le Lannic for FE-SEM images performed at CMEBA (ScanMAT, UMS 2001 CNRS-University of Rennes 1) which received a financial support from the Région Bretagne and the European Union (CPER-FEDER 2007-2014, Présage $n^{\circ} 39126$ and Présage $\left.n^{\circ} 37339\right)$. 


\section{$\underline{\text { References }}$}

[1] Kong L B, Li S, Zhang T S, Zhai J W, Boey F Y C and Ma J (2010) Electrically tunable dielectric materials and strategies to improve their performances, Prog. Mater Sci. 55:840-93

[2] Gevorgian S (2009) Ferroelectrics in microwave devices, circuits and systems : physics, modelling, fabrication and measurements, Springer, London

[3] Simon Q, Corredores Y, Castel X, Benzerga R, Sauleau R, Mahdjoubi K, Le Febvrier A, Députier S, Guilloux-Viry M, Zhang L, Laurent P and Tanné G (2011) Highly tunable microwave stub resonator on ferroelectric $\mathrm{KTa}_{0.5} \mathrm{Nb}_{0.5} \mathrm{O}_{3}$ thin film, Appl. Phys. Lett. 99:092904

[4] Kim H-S, Kim H-G, Kim I-D, Kim K-B and Lee J-C (2005) High-tunability and low-microwave-loss $\mathrm{Ba}_{0.6} \mathrm{Sr}_{0.4} \mathrm{TiO}_{3}$ thin films grown on high-resistivity $\mathrm{Si}$ substrates using $\mathrm{TiO}_{2}$ buffer layers, Appl. Phys. Lett. 87:212903

[5] Ren W, Trolier-McKinstry S, Randall C A and Shrout T R (2001) Bismuth zinc niobate pyrochlore dielectric thin films for capacitive applications, J. Appl. Phys. 89:767-74

[6] Thayer R L, Randall C A and Trolier-McKinstry S (2003) Medium permittivity bismuth zinc niobate thin film capacitors, J. Appl. Phys. 94:1941-7

[7] Nino J C, Lanagan M T and Randall C A (2001) Dielectric relaxation in $\mathrm{Bi}_{2} \mathrm{O}_{3}-\mathrm{ZnO}--\mathrm{Nb}_{2} \mathrm{O}_{5}$ cubic pyrochlore, J. Appl. Phys. 89:4512-6

[8] Zhang X, Ren W, Shi P, Wu X, Chen X and Yao X (2013) Structures and dielectric properties of pyrochlore bismuth zinc niobate thin films with zinc compensation, J. Alloys Compd. 553:8-13

[9] Hong Y P, Ha S, Lee H Y, Lee Y C, Ko K H, Kim D-W, Hong H B and Hong K $\mathrm{S}$ (2002) Voltage tunable dielectric properties of rf sputtered $\mathrm{Bi}_{2} \mathrm{O}_{3}-\mathrm{ZnO}-\mathrm{Nb}_{2} \mathrm{O}_{5}$ pyrochlore thin films, Thin Solid Films 419:183-8

[10] $\mathrm{Lu} \mathrm{J}$ and Stemmer S (2003) Low-loss, tunable bismuth zinc niobate films deposited by rf magnetron sputtering, Appl. Phys. Lett. 83:2411-3

[11] Cao L Z, Fu W Y, Wang S F, Wang Q, Sun Z H, Yang H, Cheng B L, Wang H and Zhou Y L (2007) $\mathrm{C}$-axial oriented $\left(\mathrm{Bi}_{1.5} \mathrm{Zn}_{0.5}\right)\left(\mathrm{Zn}_{0.5} \quad \mathrm{Nb}_{1.5}\right) \mathrm{O}_{7}$ thin film grown on $\mathrm{Nb}$ doped $\mathrm{SrTiO}_{3}$ substrate by pulsed laser deposition, J. Phys. D: Appl. Phys. 40:1460-3

[12] Le Febvrier A, Galca A-C, Corredores Y, Députier S, Bouquet V, Demange V, Castel X, Sauleau R, Lefort R, Zhang L, Tanné G, Pintilie L and Guilloux-Viry 
M (2012) Structural, optical and dielectric properties of $\mathrm{Bi}_{1.5-\mathrm{x}} \mathrm{Zn}_{0.92-\mathrm{y}} \mathrm{Nb}_{1.5} \mathrm{O}_{6.92-\delta}$ thin films grown by PLD on R-plane sapphire and LaAlO3 substrates, ACS Appl. Mater. Interfaces 4:5227-33

[13] Zhang X, Ren W, Shi P, Tian A, Xin H, Chen X, Wu X and Yao X (2010) Influence of substrate temperature on structures and dielectric properties of pyrochlore $\mathrm{Bi}_{1.5} \mathrm{Zn}_{1.0} \mathrm{Nb}_{1.5} \mathrm{O}_{7}$ thin films prepared by pulsed laser deposition, Appl. Surf. Sci. 256:6607-11

[14] Al Garni S E, Qasrawi A F and Mergen A (2016) Physical properties of the $\mathrm{Bi}_{1.5} \mathrm{Zn}_{0.92-2 \mathrm{x}} \mathrm{Hf}_{\mathrm{X}} \mathrm{Nb}_{1.5} \mathrm{O}_{6.92}$ solid solutions, Ceram. Int. 42:3372-9

[15] Michael E K and Trolier-McKinstry S (2015) Cubic Pyrochlore Bismuth Zinc Niobate Thin Films for High-Temperature Dielectric Energy Storage, J. Am. Ceram. Soc. 98:1223-9

[16] Lee Y C, Hong Y P, Kim D M and Ko K H (2006) Very high tunable inter-digital capacitor using bismuth zinc niobate thin-film dielectrics for microwave applications, Electron. Lett. 42:851-3

[17] Lee Y C and Ko K H (2010) Tunable coplanar waveguide (CPW line integrating bismuth zinc niobiate (BZN) thin films, Progress In Electromagnetics Research Letters 19:75-82

[18] Cao L Z, Fu W Y, Wang S F, Wang Q, Sun Z H, Yang H, Cheng B L, Wang H and Zhou Y L (2007) Effects of film thickness and preferred orientation on the dielectric properties of $\left(\mathrm{Bi}_{1.5} \mathrm{Zn}_{0.5}\right)\left(\mathrm{Zn}_{0.5} \mathrm{Nb}_{1.5}\right) \mathrm{O}_{7}$ films, J. Phys. D: Appl. Phys. 40:2906-10

[19] Duclère J R, Mc Loughlin C, Fryar J, O'Haire R, Guilloux-Viry M, Meaney A, Perrin A, McGlynn E, Henry M O and Mosnier J P (2006) ZnO thin films grown on platinum (111) buffer layers by pulsed laser deposition, Thin Solid Films 500:78-83

[20] Valant M and Davies P K (1999) Synthesis and dielectric properties of pyrochlore solid solutions in the $\mathrm{Bi}_{2} \mathrm{O}_{3}-\mathrm{ZnO}-\mathrm{Nb}_{2} \mathrm{O}_{5}-\mathrm{TiO}_{2}$ system, Journal of Materials Science 34:5437-42

[21] Roisnel T, Rodriguez-Carvajal J (2001) WinPLOTR: A Windows tool for powder diffraction pattern analysis, Mater Sci Forum. 378-3: 118-123

[22] Le Febvrier A, Députier S, Bouquet V, Demange V, Ollivier S, Galca A C, Dragoi C, Radu R, Pintilie L and Guilloux-Viry M (2012) Ferroelectric and dielectric multilayer heterostructures based on $\mathrm{KTa}_{0.65} \mathrm{Nb}_{0.35} \mathrm{O}_{3}$ and $\mathrm{Bi}_{1.5-\mathrm{x}} \mathrm{Zn}_{0.92-\mathrm{y}} \mathrm{Nb}_{1.5} \mathrm{O}_{6.92-1.5 \mathrm{x}-\mathrm{y}}$ grown by pulsed laser deposition and chemical 
solution deposition for high frequency tunable devices, Thin Solid Films 520:4564-7

[23] Wang X, Wang H and Yao X (1997) Structures, Phase Transformations, and Dielectric Properties of Pyrochlores Containing Bismuth, J. Am. Ceram. Soc. 80:2745-8

[24] Nefedov A, Abromeit A, Morawe C and Stierle A (1998) High-resolution x-ray scattering study of platinum thin films on sapphire, J. Phys.: Condens. Matter 10:717-30

[25] Vargas R, Goto T, Zhang W and Hirai T (1994) Epitaxial growth of iridium and platinum films on sapphire by metalorganic chemical vapor deposition, Appl. Phys. Lett. 65:1094-6

[26] Li H-C, Si W, West A D and Xi X X (1998) Thickness dependence of dielectric loss in $\mathrm{SrTiO}_{3}$ thin films, Appl. Phys. Lett. 73:464-6

[27] Oh J, Moon T, Kim T-G, Kim C, Lee J H, Lee S Y and Park B (2007) The dependence of dielectric properties on the thickness of $(\mathrm{Ba}, \mathrm{Sr}) \mathrm{TiO}_{3}$ thin films Current Applied Physics 7:168-71

[28] Yang L, Ponchel F, Wang G, Remiens D, Legier J-F, Chateigner D and Dong X (2010) Microwave properties of epitaxial (111)-oriented $\mathrm{Ba}_{0.6} \mathrm{Sr}_{0.4} \mathrm{TiO}_{3}$ thin films on $\mathrm{Al}_{2} \mathrm{O}_{3}(0001)$ up to $40 \mathrm{GHz}$, Appl. Phys. Lett. 97:162909-3

[29] Liu Y, Withers R, Welberry T R, Wang H, Du H-L and Yao X (2008) Structural disorder in BZN-based pyrochlores, J. Electroceram. 21:401-4

[30] Liu Y, Withers R L, B.Nguyen and Wei X Y (2007) Towards the development of high-performance, frequency agile, Rf/microwave dielectric ceramins based on nanoscale structural analysis, Australian Ceramic Society 43:75-8

[31] Wei W, Pingfan N, Jinglu F and Weixing W (2014) Mechanism of dielectric nonlinear characteristics in bismuth-based cubic pyrochlores, Ceram. Int. 40:13841-5

[32] Brooks Hinojosa B, Asthagiri A and Nino J C (2013) Energy landscape in frustrated systems: Cation hopping in pyrochlores, Appl. Phys. Lett. 103:022901

[33] Kamba S, Porokhonskyy V, Pashkin A, Bovtun V, Petzelt J, Nino J C, Trolier-McKinstry S, Lanagan M T and Randall C A (2002) Anomalous broad dielectric relaxation in $\mathrm{Bi}_{1.5} \mathrm{Zn}_{1.0} \mathrm{Nb}_{1.5} \mathrm{O}_{7}$ pyrochlore, Phys. Rev. B 66:054106 
